\title{
Proof of bacteria and the activity of chemical and natural antibiotics by headspace gas chromatography
}

\author{
Bruno Konrad Kolb $b^{1,2^{*}}$ (D) Lorina Riesterer ${ }^{1,3}$, Leona Bier ${ }^{1,4}$ and Anna-Maria Widenhorn ${ }^{1,5}$
}

\begin{abstract}
An efficient technique was developed to monitor the emission of hydrogen and carbon dioxide from bacteria cultures by headspace gas chromatography and to investigate the efficacy of chemical antibiotics and of natural compounds with antimicrobial properties. Facultative anaerobes emit hydrogen and carbon dioxide from cultures in the closed headspace vials and obligate anaerobes too, if the air above the cultures in the vials is replaced by nitrogen. Antibiotics added to the sample cultures are apparently effective if the emission of hydrogen and carbon dioxide is suppressed. If not, either they are ineffective or the related bacteria are even resistant. The headspace technique can detect bacterial contamination in various samples, and examples are presented for food purchased from supermarkets and for medical specimens, including recognition of antibiotic resistance. However, the described technique cannot identify the related bacteria at a species or genus level, but is well suited for example for screening the bulk of food in supermarkets for microbe contamination or for the search of natural antibiotics. The samples are incubated with the proper nutrient medium in closed septum vials which remain closed during the whole process. The personnel in the lab never come into contact with pathogens, and thus, safety regulations are warranted. The described technique can be carried out with all commercially available gas chromatographs, even including simple low-cost instruments, equipped with a standard packed column and a thermal conductivity detector, up to expensive and fully automated instruments, such as used for forensic blood alcohol analysis.
\end{abstract}

Keywords: Bacteria, Antibiotics, Antibiotic resistance, Headspace gas chromatography

\section{Introduction}

Bacteria emit volatile compounds, which are amenable to analysis by gas chromatography. In particular, static headspace gas chromatography (HS-GC) is well suited to analyze volatile compounds (VOCs) from bacterial cultures enclosed in septum vials. Although the composition of the emitted VOCs contains much information, the pattern produced is in general not sufficiently informative to identify the actual species but nevertheless allows bacterial contamination in various samples such as household requisites, food, medical specimens, and several more to be determined. HS-GC is an

\footnotetext{
* Correspondence: kolbbn@t-online.de

${ }^{1}$ Student Research Centre, Gymnasium Überlingen, Obertorstrasse 16, 88662 Überlingen, Germany

${ }^{2}$ Dipl.Chem, Im Weingärtle 16, 88696 Owingen, Germany

Full list of author information is available at the end of the article
}

established automated analytical tool and is well suited for screening applications to process a large number of samples. This is particularly useful in the search for natural compounds with antimicrobial properties as an alternative to the increasing number of multi-resistant chemical antibiotics which have lost their efficacy. Antimicrobial resistance is a serious and current issue in medicine. For this reason, novel antibiotics are needed to treat such multi-resistant microbes [1]. There is growing interest in searching for natural compounds with biocide properties. Such research however requires investigations with a large number of measurements, and this need calls urgently for automation. Gas chromatography is a well-established automated analytical technique and can be applied to enhance such automated research. In particular, automated HS-GC is well suited to analyze VOCs emitted from bacterial cultures 


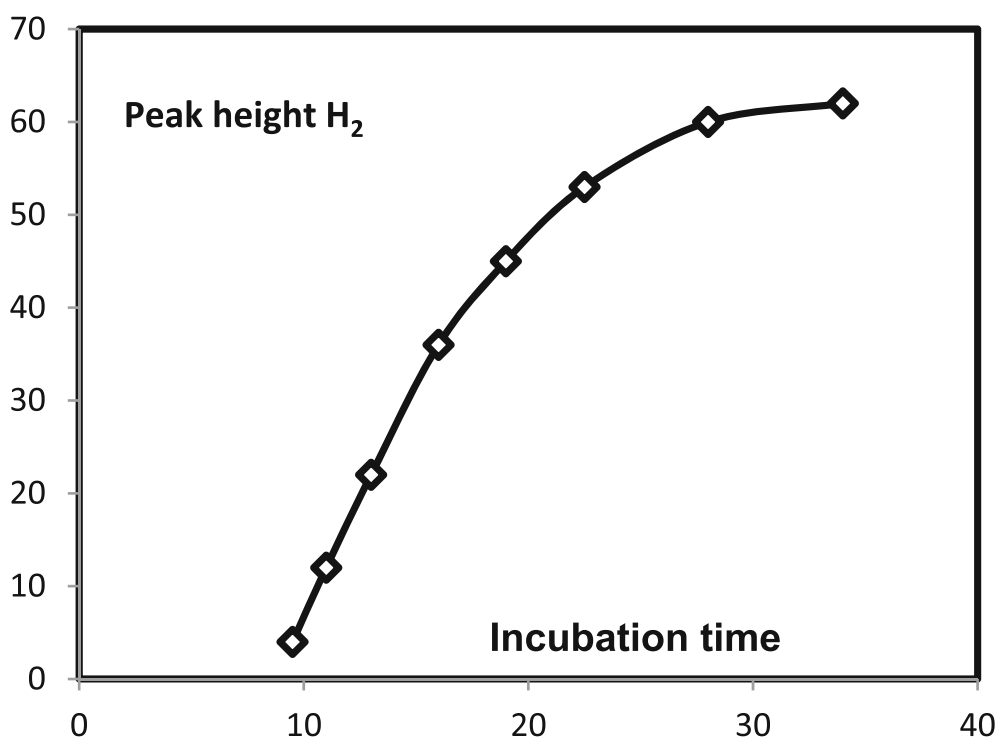

Fig. 1 Incubation times (hours) for bacterial analysis from a smear taken from a kitchen cloth. Peak heights in arbitrary units. GC-column 1: silica gel

[2, 3]. Although VOCs were the class of compounds that received the most study, particularly free fatty acids emitted from bacterial cultures [4], even non-volatile organic acids are found amenable to static HS-GC after derivatization [5]. As an alternative to static HS-GC, the technique of headspace solid-phase microextraction (HS-SPME) followed by gas chromatography-mass spectrometry (GC-MS) has also been applied to study VOCs $[6,7]$. The study presented here is focused on the determination of emitted hydrogen $\left(\mathrm{H}_{2}\right)$ and carbon dioxide $\left(\mathrm{CO}_{2}\right)$ to recognize bacterial contamination in various samples and to study the activity of chemical and natural antibiotics. For each of such applications, a typical example is presented.

\section{Materials and instrumentation}

Gas chromatograph AK-GC 11, Aug.Hedinger GmbH \& Co KG; GC-column 1: $0.8 \mathrm{~m} \times 6 \mathrm{~mm}$ polyamid tube, silica gel, 60/80 mesh, GC-column 2: $0.8 \mathrm{~m} \times 6 \mathrm{~mm}$ polyamid tube, Chromosorb 102, 60/80 mesh; room temperature; carrier gas: ambient air, $10 \mathrm{ml} / \mathrm{min}$; headspace vials: $6 \mathrm{ml}$ from PerkinElmer crimp-capped with PTFE-laminated butyl rubber septa. Data system: HP-Notebook. Nutrient medium: heipha, Dr. Müller $\mathrm{GmbH}$, tryptic soy broth acc EP+ USP 3080r-20p; composition: pancreatic digest of casein, $17 \mathrm{~g}$; papaic digest of soya bean meal, $3 \mathrm{~g}$; sodium chloride, $5 \mathrm{~g}$; dipotassium hydrogen phosphate, $2.5 \mathrm{~g}$; glucose monohydrate.

\section{Method}

Static HS-GC was applied to identify the various classes of bacteria by analysis of $\mathrm{H}_{2}$ and $\mathrm{CO}_{2}$ emerging from microorganisms. Obligate aerobic bacteria produce $\mathrm{CO}_{2}$ and water by oxidation of the nutrient medium. Facultative anaerobes can exist both in an air environment as well as under reduced oxygen conditions and can thus emit both $\mathrm{CO}_{2}$ and $\mathrm{H}_{2}$. For these classes of bacteria, the significant compounds are $\mathrm{H}_{2}$ and $\mathrm{CO}_{2}$. Obligate anaerobic bacteria in addition to $\mathrm{H}_{2}$ produce many other organic compounds, such as free fatty acids, alcohols, and several more [2], but cannot survive atmospheric levels of oxygen. If, however, the air in the vials is replaced by flushing with nitrogen gas, these bacteria can thrive. The samples under investigation, either solid or liquid samples and also the cotton head from a cotton bud as used for a smear, are cultured in septum vials together with nutrient medium. After the necessary time of incubation, the volatile compounds in the gas phase in the vials are analyzed by HS-GC. Antibiotics added to the bacterial cultures in the vials are effective if any gas emission is suppressed. If not, either they are ineffective or the related bacteria are resistant.

\section{Results}

Interpretation of chromatograms

A simple gas chromatograph, even though restricted to operation at room temperature only, was found to be sufficient to separate both $\mathrm{H}_{2}$ and $\mathrm{CO}_{2}$. Since our main interest was the determination of $\mathrm{H}_{2}$, ambient air was used as carrier gas to achieve a high sensitive response with a positive peak due to the big difference in heat conductivity 


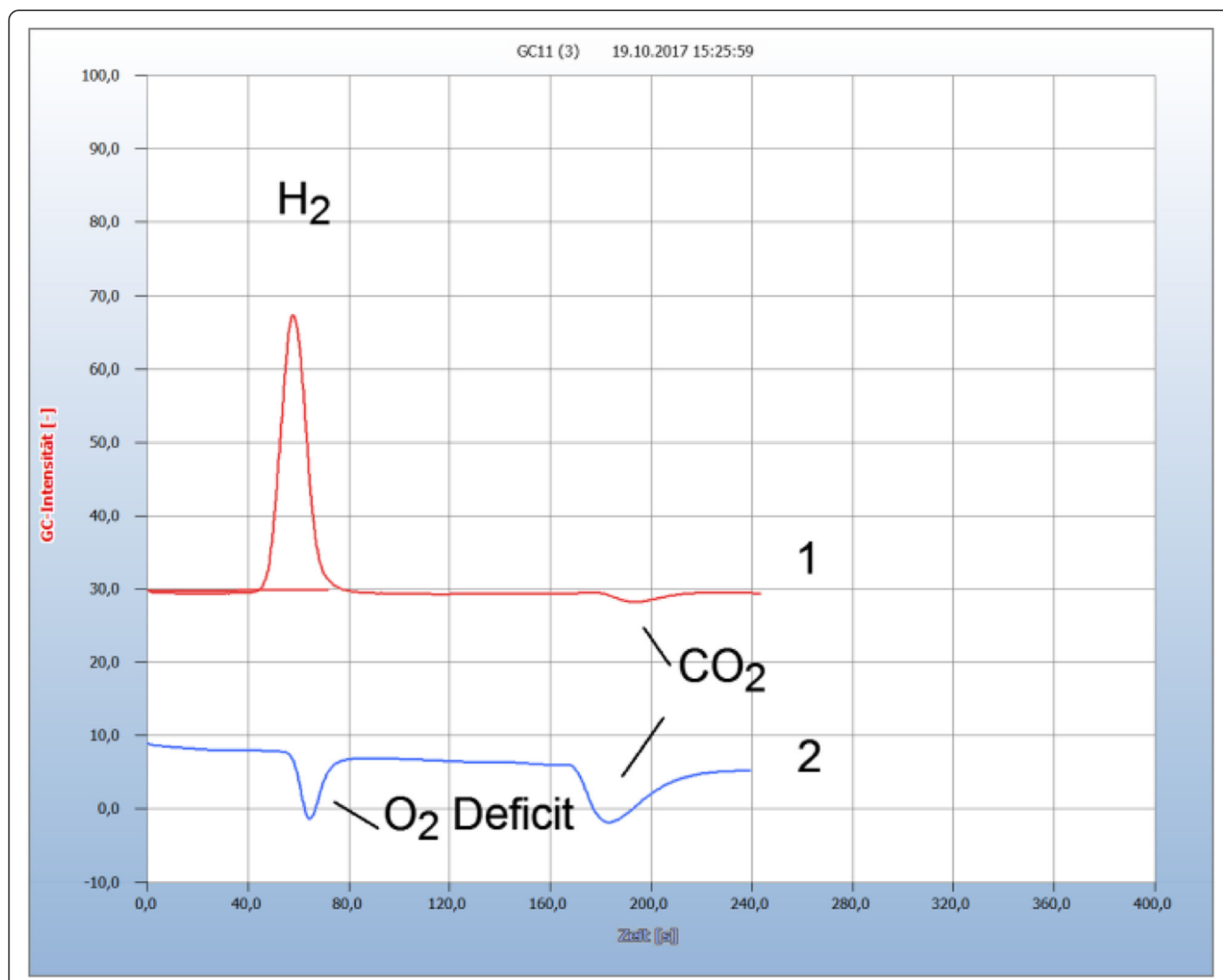

Fig. 2 Facultative anaerobic (1) and obligate aerobic (2) bacteria in salad samples. 1, packaged chopped salad; 2, unpackaged bio-salad. GCcolumn 1: silica gel

by the thermal conductivity detector. On the other hand, $\mathrm{CO}_{2}$ produces a negative peak in the chromatogram due to its lower heat conductivity in the stream of ambient air and the detector response, although less sensitive, was found to be sufficient for the intended purpose of $\mathrm{CO}_{2}$ detection. Figures 2, 3, 4, 5, 6, and 7 are typical chromatograms. Another negative peak often found at the rear of the hydrogen peak is caused by a change in the gas composition in the headspace vials. Aerobic and also facultative anaerobic bacteria consume oxygen to produce $\mathrm{CO}_{2}$, and thus, the oxygen concentration of ambient air in the headspace gas in the closed vials is reduced and the nitrogen concentration enhanced. This altered gas sample, withdrawn for analysis, has a lower heat conductivity compared with the ambient air used as carrier gas. A negative peak is thus created, corresponding to the retention time of air on this particular column. The missing oxygen however is not lost but transferred to $\mathrm{CO}_{2}$. Obligate aerobic bacteria therefore produce two negative peaks, the peak corresponding to the oxygen deficit and the $\mathrm{CO}_{2}$ peak at the end of the chromatogram. However, since this first negative peak may also be caused by some oxidation of sensitive compounds in the sample or in the nutrient medium, often depending on the length of incubation time, only the $\mathrm{CO}_{2}$ peak should be considered significant for aerobes and also for facultative anaerobes, which can exist both in oxygen and oxygen-reduced atmospheres. At the beginning of incubation, facultative anaerobes start emitting $\mathrm{CO}_{2}$, but as the oxygen content steadily declines in the atmosphere in the vials, the bacteria change from the oxidation to the fermentation process, thus producing $\mathrm{H}_{2}$. All given chromatograms were obtained using the GC-column with silica gel, except that in Fig. 7 with Chromosorb 102. The latter column separates the 


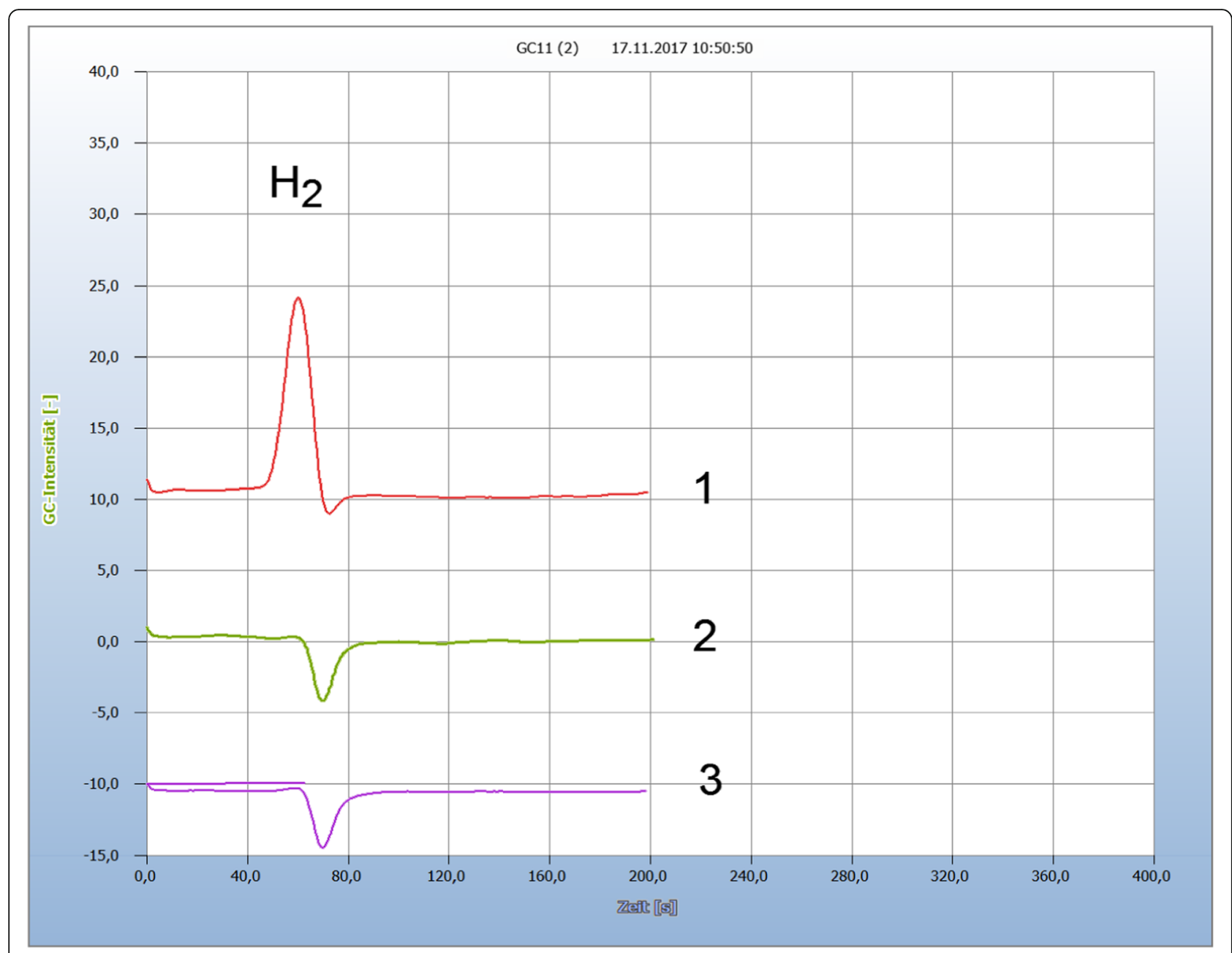

Fig. 3 Obligate bacteria in the colon. 1, sample under nitrogen atmosphere in the vial; 2, sample under ambient air in the vial; 3, blank of pure cotton head from cotton bud in nutrient medium. GC-column 1: silica gel

negative peak of the $\mathrm{O}_{2}$ deficit slightly better from the rear of the hydrogen peak, but $\mathrm{CO}_{2}$ on the other hand has an excessive long retention time and for this reason this column may be preferred when only the hydrogen emission is of analytical interest.

\section{Sample preparation and incubation time}

The samples under investigation were placed into the headspace vials of $6 \mathrm{ml}$ volume together with $2.5 \mathrm{ml}$ nutrient medium and capped with a PTFE-laminated septum. Solid samples were usually cut; about 50$100 \mathrm{mg}$ was placed in the liquid nutrient medium; and from liquid samples, $50-100 \mu \mathrm{l}$ was added. If the efficacy of antibiotics is being tested, a few milligrams of the solid powder were added. Smears were collected by sterilized cotton bud and the cotton head transferred into the liquid nutrient medium. These samples were incubated at $37^{\circ} \mathrm{C}$, and as shown from the kinetic of hydrogen emission in Fig. 1 from a sample of a wet kitchen cloth, a reasonable hydrogen signal is achieved already after an overnight incubation period of about $12 \mathrm{~h}$. A constant hydrogen signal required about $30 \mathrm{~h}$ for this particular sample. Such a constant hydrogen signal would be required if for quantitative analysis the concentration of the related bacteria should be correlated with hydrogen emission. Due to the difficulty of preparing the necessary calibration standard, any quantitative attempts were omitted, particularly because the HS-GC method is preferably used for screening applications. The wet kitchen cloth used here as an example is known to contain a mixed population of many different bacteria. It is therefore a good source to investigate and to compare the general efficiency of antibiotics. The necessary incubation time, however, can vary with the type of bacteria and may also depend on the original bacterial concentration in the sample, until the necessary amount of $\mathrm{H}_{2}$ is produced by the growing 


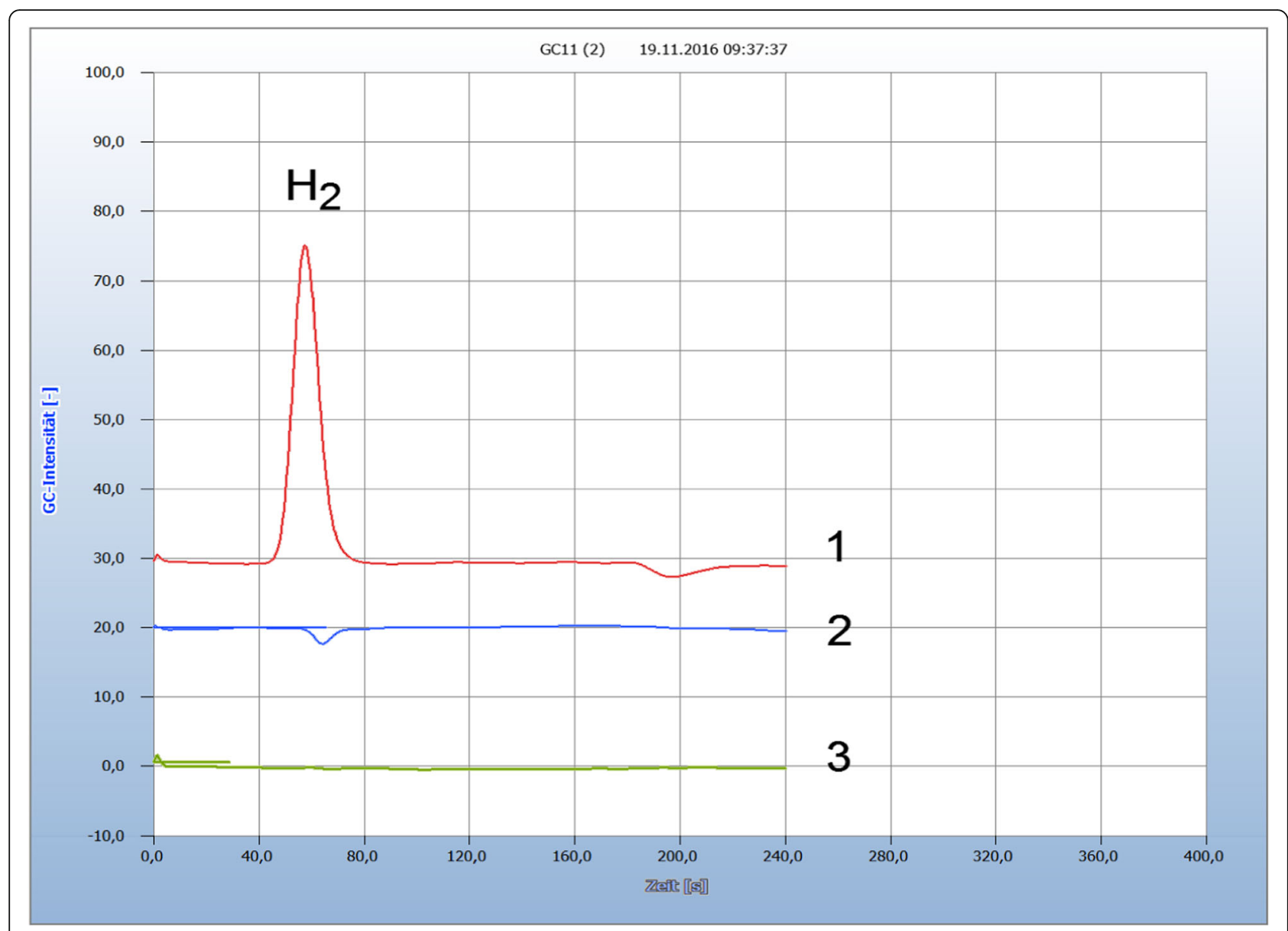

Fig. 4 Efficacy of oil of cloves. 1, fish; 2, added streptomycin; 3, added oil of cloves. GC-column 1: silica gel

bacteria population. For this reason, we used in general a 1-day incubation time and if $\mathrm{H}_{2}$ or $\mathrm{CO}_{2}$ was not yet found, we repeated the analysis 1 day later to be on the safe side. Some bacteria, e.g., Spirochaetes, need longer incubation due to slow reproduction, and for such samples, 2 to 3 days were sometimes found to be necessary.

\section{Proof of aerobic, anaerobic, and facultative anaerobic bacteria}

The three main classes of bacteria, aerobics, anaerobics, and facultative anaerobics, can be determined by their significant volatile compounds in the gas chromatogram. An example is shown in Figs. 2 and 3. Figure 2 presents the results from two salad samples, one of these a packaged salad with a hydrogen peak and the other an open salad without a hydrogen peak, the latter also declared as bio-salad. It is known that chopped salad packaged in plastic containers is often contaminated by the facultative anaerobe Salmonella creating the hydrogen peak, while the bio-salad apparently was contaminated by obligate aerobes only, as indicated by the missing hydrogen peak and by the negative carbon dioxide peak. Both salad samples were incubated $15 \mathrm{~h}$ without nutrient medium in the vials.

While Fig. 2 gives examples on how to identify aerobes and facultative anaerobes, the unambiguous proof of obligate anaerobes is given in Fig. 3 on the example of a smear from the colon. The colon contains mainly the obligate anaerobic bacteria Clostridia, together with a minor population of Eschericia coli. The hydrogen peak no. 1 in Fig. 3 is caused by Clostridia in the colon sample under nitrogen atmosphere in the vial, while air in the vial prevented the hydrogen production (no. 2). The simple headspace vial under a nitrogen atmosphere thus replaced the common anaerobic chamber necessary particularly for investigations of obligate anaerobes, mainly Clostridia. No. 3 in Fig. 3 is the result of the blank of the pure cotton head from a cotton bud in the nutrient medium. These examples demonstrate the possibility to differentiate the classes of bacteria, but it must be again admitted that the HS-GC method does not allow to identify the related species in each class of bacteria. 


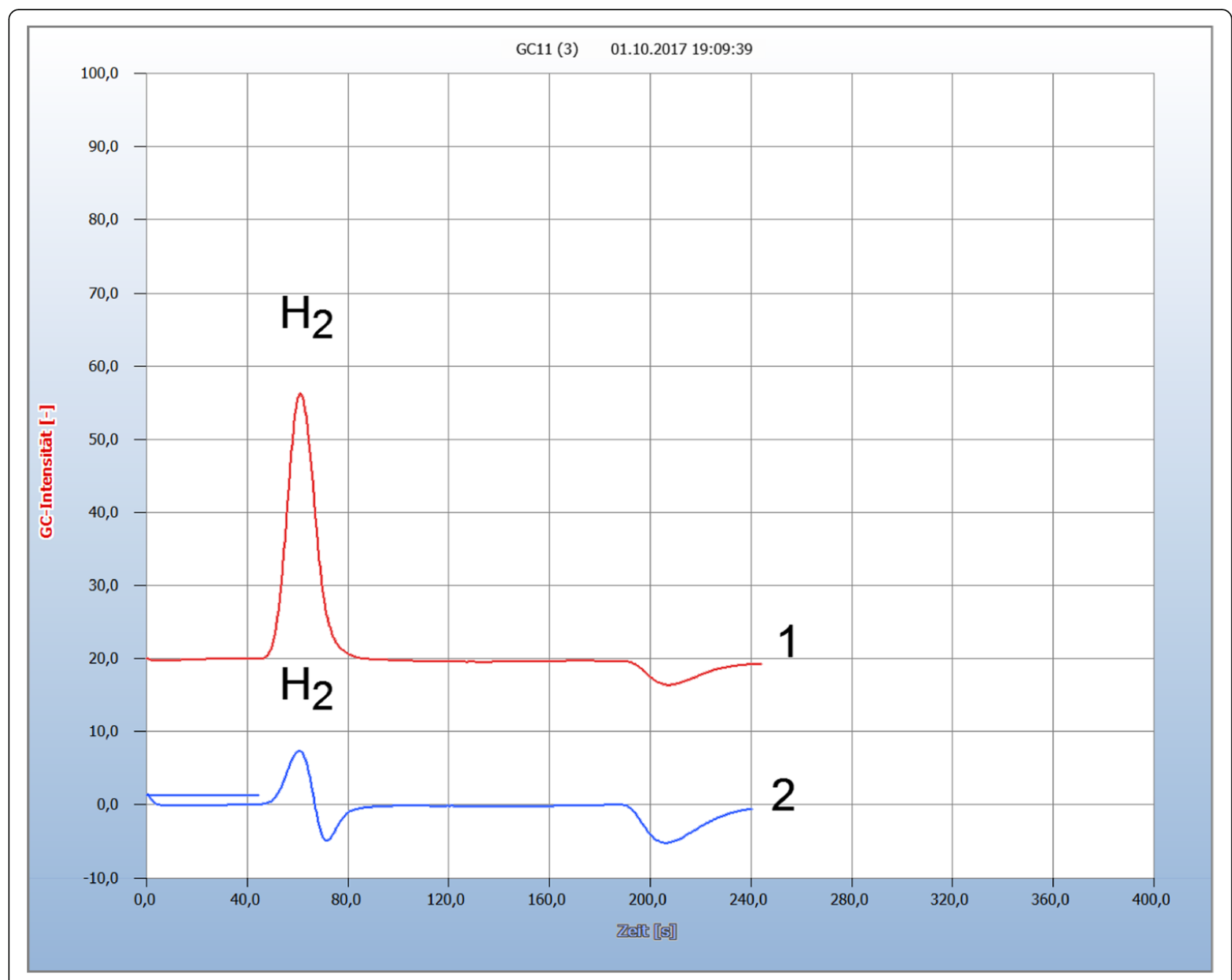

Fig. 5 Antibiotic resistance in the leg of a chicken. 1, leg of chicken; 2, added penicillin. GC-column 1: silica gel

\section{Comparison of natural and pharmaceutical antibiotics}

Besides the common chemical antibiotics, there are a number of natural products with antimicrobial properties, and from these, a selection comprising propolis, white currant oil, teasel, or pine tree resin has been investigated but with varying success only. The most effective compounds have been oil of cloves, garlic, and seeds of cress. Figure 4 gives as an example a comparison between the chemical antibiotic streptomycin and oil of cloves, applied to a contaminated fish from a supermarket from which small pieces were incubated in the nutrient medium and apparently both antibiotics worked equally well as indicated by the missing hydrogen peak. However, the active agent in the oil of cloves is up to now not known; it probably could be a phenolic compound, e.g., eugenol. Other essential oils with supposed antimicrobial properties investigated during this work showed no antimicrobial effect. But both rough cut garlic and dragees with pulverized garlic and also seed of cress were found to have the same antimicrobial properties.

\section{Proof of microbes in contaminated food samples}

The use of antibiotics in food-producing animals causes the growing concern of antibiotic resistance since antibiotic-resistant bacteria may be transmitted to humans through the food supply. Food from supermarkets is often contaminated by microbes, e.g., fish, turkey, or chicken. The GC procedure also enables antimicrobial resistance to be detected, and such an example is given in Fig. 5. The legs of chicken apparently were contaminated by microbes, but penicillin if added to the chicken sample in the vial did not eliminate hydrogen emission. Obviously, the animals in a chicken farm treated by excessive antibiotic application became resistant [8]. It was found by the German Bundesamt für Verbraucherschutz und Lebensmittelsicherheit (German 
Federal Agency for Consumer Protection and Food Safety) that about $75 \%$ of such chicken samples in supermarkets were infected by Camphylobacter bacteria. Another similar example of antimicrobial resistance was found with amoxycillin in contaminated turkey.

\section{Diagnosis of bacterial infection by HS-GC of clinical specimens and antimicrobial therapy}

An important application is the search for effective antibiotics in both veterinary and human medicine. Figure 6 gives the result of searching for a suitable antibiotic in the case of a rabbit with inflamed nose and mouth. Unfortunately, this animal treated by the veterinary with amoxycillin died since apparently this antibiotic was the wrong drug, but treated with tetracycline, the rabbit probably would have survived. Cows often suffer from inflamed udders, and in this case, bacteria such as Streptococcus or Staphylococcus are found in the milk and such an example is given in Fig. 7. This sample was analyzed separately by standard microbiological tests, and Streptococcus bacteria were identified but were found to be resistant against penicillin [9], while enrofloxacin was effective as shown in Fig. 7.

\section{Discussion}

Static HS-GC was applied to detect bacteria contamination in various samples, such as food, household requisites, and medical specimens. For each of these selected applications, one typical example is presented. Natural substances with biocide properties were compared with chemical antibiotics for their suitability as alternative antibiotics. The described method, however, cannot identify each bacterium at a genus or species level. The HS-GC technique has the unique advantage that the whole procedure is carried out in hermetically closed vials, this already beginning with the sample preparation. When the samples are inserted into the nutrient medium, the headspace vials are capped with PTFE-lined septa and sealed with a crimped closure. The septum is then pierced with the needle of a gas syringe, and about $0.3 \mathrm{ml}$ of the headspace gas is withdrawn and injected into the gas chromatograph. The septum remains tight, and several gas samples can be analyzed at given time intervals, thus enabling kinetic measurements. After analysis, the closed vials with their contents can be sterilized at the necessary

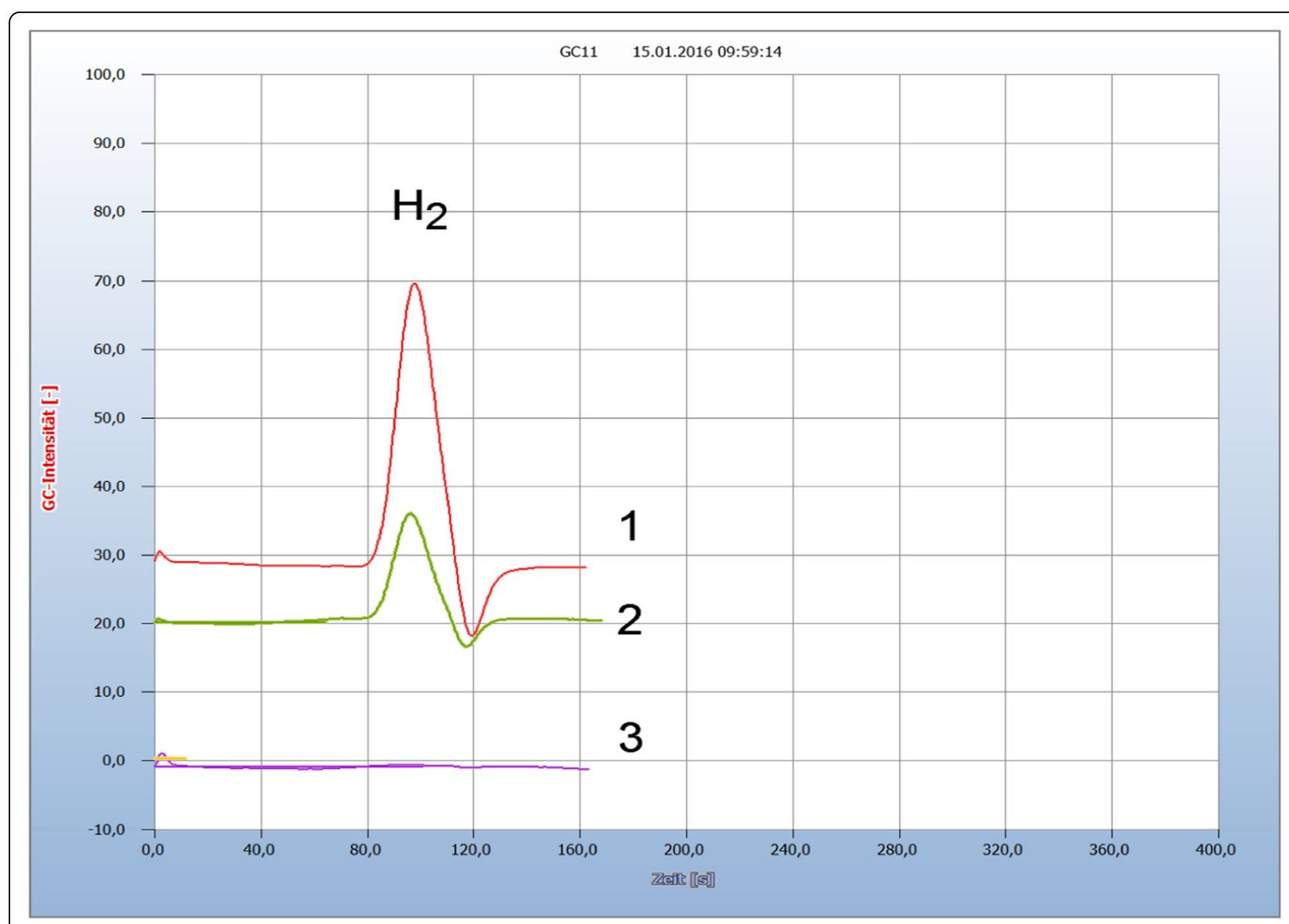

Fig. 6 Antibiotic resistance against amoxycillin. 1, rabbit with inflamed nose and mouth; 2, added amoxycillin; 3, added tetracycline. GC-column: Chromosorb 102 


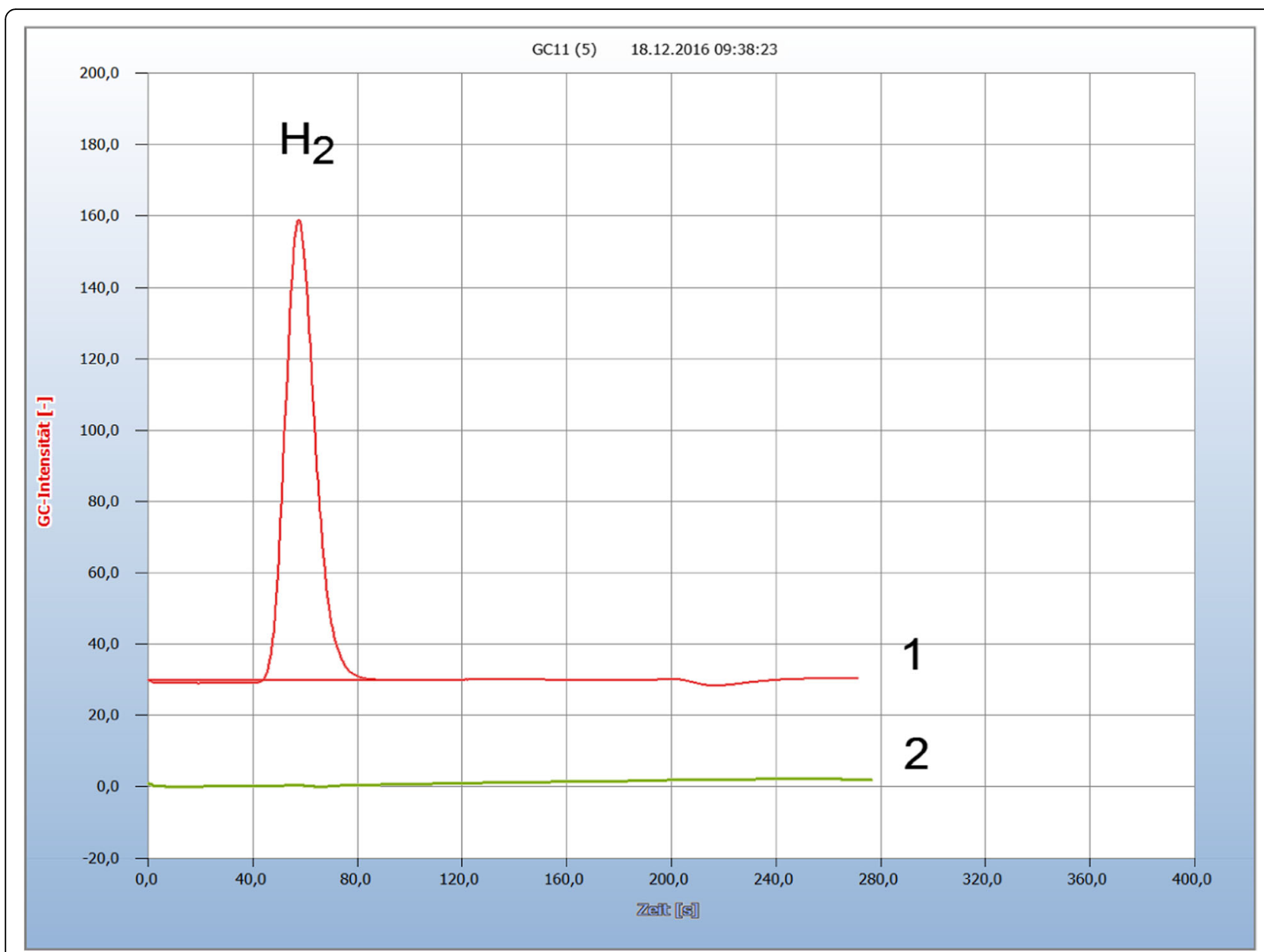

Fig. 7 Efficacy of enrofloxacin against Streptococcus in milk. 1, contaminated milk; 2, added enrofloxacin. GC-column 1: silica gel

high temperature and then safely discarded. Thus, the personnel in a lab never come into contact with pathogens. With commercially available instruments for automated HS-GC, up to 100 samples can be processed automatically with high throughput due to the short analysis time of $3 \mathrm{~min}$. This technique is thus particularly suited for screening purposes to analyze a large number of samples, such as food, for potential contamination by microorganism or to search for alternative antibiotics in case of antibiotic resistance. Contaminated samples then may be taken for further investigations to identify the related microorganism. The electrical signal generated by such an automated headspace instrument lends itself to automated computer evaluation and documentation.

\section{Abbreviations}

$\mathrm{CO}_{2}$ : Carbon dioxide; EP: European Pharmacopoeia; GC: Gas chromatography; GC-MS: Gas chromatography-mass spectrometry; $\mathrm{H}_{2}$ : Hydrogen; HS-

GC: Headspace gas chromatography; HS-SPM: Headspace solid-phase microextraction; PTFE: Polytetrafluoroethylene; USP: United States Pharmacopoeia; VOCs: Volatile organic compounds
Acknowledgements

We thank Baden-Württemberg Stiftung for financial support (500 US\$) and PerkinElmer LAS (Germany) GmbH for material supply (100 headspace vials).

\section{Author's instruction}

The present study presents a novel technique to monitor the emission of hydrogen and carbon dioxide as specific compounds of all facultative anaerobes by headspace gas chromatography. The described method is particularly suited for screening applications to handle a large number of samples for possible microbe contamination. Such samples can then be selected for further investigations by well-established approaches, but any attempts to identify the related bacteria with proven methods could not be undertaken in our student research centre because handling of open bacteria cultures was not allowed due to safety restrictions. But our method can be applied to investigate the antimicrobial efficacy of chemical and natural antibiotics.

\section{Funding}

This work was supported by Baden-Württemberg Stiftung and by PerkinElmer LAS (Germany) GmbH.

\section{Availability of data and materials}

Data sharing not applicable to this article as no datasets were generated or analysed during the current study. Please contact author for data requests. 


\section{Authors' contributions}

The initial idea and concept of this study was suggested by BKK who also prepared the manuscript, due to the need to write it in English, while the analytical technique was developed and evaluated by $L R$, LB, and A-MW, including the selection and investigations of the various applications. LR investigated the microbial contamination of food, LB the antimicrobial activities of essential oils and other natural substances, and A-MW the antibiotic resistance of bacteria in medical specimens. One representative example from al these applications is presented in the manuscript. All authors read and approved the final manuscript.

\section{Competing interests}

The authors declare that they have no competing interests.

\section{Publisher's Note}

Springer Nature remains neutral with regard to jurisdictional claims in published maps and institutional affiliations.

\section{Author details}

'Student Research Centre, Gymnasium Überlingen, Obertorstrasse 16, 88662 Überlingen, Germany. ${ }^{2}$ Dipl.Chem, Im Weingärtle 16, 88696 Owingen, Germany. ${ }^{3}$ Am Häslerain 36, 78354 Sipplingen, Germany. ${ }^{4}$ Goldbach 24, 88662 Überlingen, Germany. ${ }^{5}$ Ostlandstr. 8, 78354 Sipplingen, Germany.

Received: 29 July 2018 Accepted: 23 January 2019

Published online: 09 February 2019

\section{References}

1. Rossolini GM, Mantengoli E. Antimicrobial resistance in Europe and its potential impact on empirical therapy. Clin. Microbiol Infec. 2008;14(6):2-8.

2. Kolb B, Ettre LS.Static headspace-gas chromatography: theory and practice, 2nd Edition, Wiley-Interscience, 2006;286-291.

3. Larsson L, Mårdh P-A, Odham G. Analysis of volatile metabolites in identification of microbes and diagnosis in infectious diseases. J Chromatogr Biomed Appl. 1984; 305:178-182.

4. Seifert SH, Böhnel H, Gierke S, Heine A, Hoffmann D, Sukop U, Boege DH. Identification of anaerobic bacteria by fatty acid pattern recognition. International Laboratory, 1986;46-56.

5. Heitefuß S, Heine A, Seifert SH. Identification of anaerobic bacteria by determination of non-volatile dicarboxylic acids after derivatization. J. Chromatog Biomed Appl. 1990;532:374-378.

6. Tait E, Perry JD, Stanforth SP, Dean JR. Identification of volatile organic compounds produced by bacteria using HS-SPME-GC-MS. J Chromatogr Sci. 2014:52(4):363-373.

7. Ghader M, Shokoufi N, Es-haghi A et al. Sol-gel-based SPME fiber as a reliable sampling technique for studying biogenic volatile organic compounds released from Clostridium tetani. Anal Bioanal Chem. 2017; 409(29):6739-6744.

8. Jansen LM, Bolck YJC, Rademaker J. et al. The analysis of tetracyclines, quinolones, macrolides, lincosamides, pleuromutilins, and sulfonamides in chicken feathers using UHPLC-MS/MS in order to monitor antibiotic use in the poultry sector. Anal Bioanal Chem. 2017;409(21):4927-4941.

9. Privat infomation from B. Martin, Staatliches Tierärtzliches Untersuchungsamt, Aulendorf, Baden- Württemberg, Germany 2016

\section{Submit your manuscript to a SpringerOpen ${ }^{\circ}$ journal and benefit from:}

- Convenient online submission

- Rigorous peer review

- Open access: articles freely available online

- High visibility within the field

- Retaining the copyright to your article

Submit your next manuscript at $\boldsymbol{\nabla}$ springeropen.com 